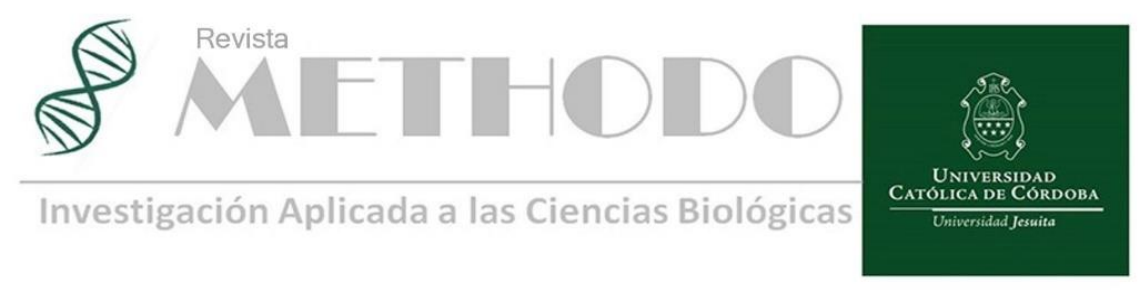

SEMBLANZA Rev. Methodo 2021;6(3):145-146

https://doi.org/10.22529/me.2021.6(3)08

Recibido 22 May. 2021 | Publicado 02 Jul. 2021

\title{
Prof. Dr. Marcelino Rusculleda Batlle (1914-1989)
}

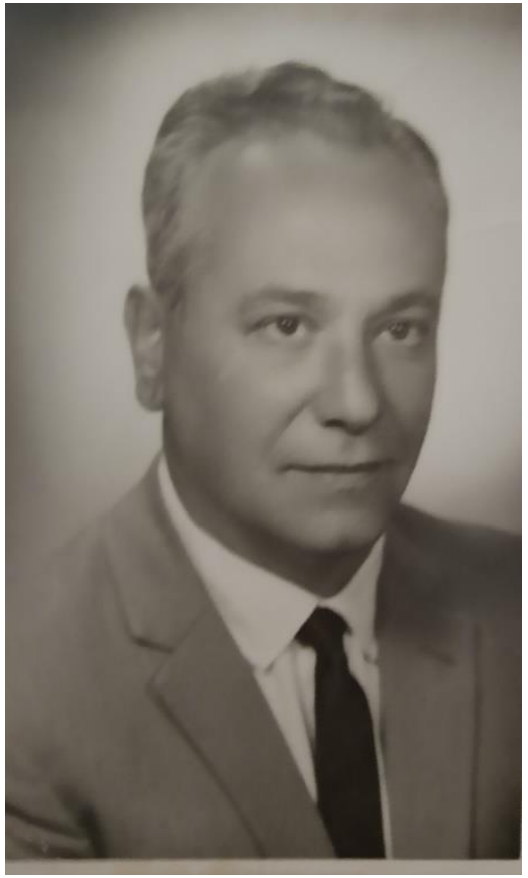

Figura 1. Prof. Dr. Marcelino Rusculleda Batlle

\section{Homenaje al profesor Dr. Marcelino Rusculleda Batlle}

Nació en la localidad de Jesús María el 30 de enero de 1914. Siendo aún niño su familia se traslada a Córdoba Capital donde transcurrieron sus estudios. Cursó el bachillerato en el colegio Monserrat y posteriormente la carrera medicina en la Universidad Nacional de Córdoba y obtuvo su diploma en el año 1940.
En el año 1945 contrajo matrimonio con Elba Spessotti. Tuvieron tres hijos, graduándose como médicos los dos varones, Marcelo quien continuó la trayectoria de su padre en la Medicina Interna, y Eduardo que se dedicó a la Cirugía.

Don Marcelino Rusculleda Batlle fue Practicante Mayor en el Hospital de Clínicas, posteriormente concursó para entrar al Hospital Córdoba en el Servicio de Cínica Médica, poco tiempo después se hizo cargo del Servicio de Cardiología del que fue Jefe de Servicio, creando allí la 1ra. Residencia de Cardiología del ámbito público, tarea que encaró con un inagotable entusiasmo inspirado en su vocación docente, como se enfatiza más adelante, logrando su objetivo con el que dejó una impronta académica en el Hospital Público, la que se prolongó hasta hoy.

Creó los Ateneos de Cardiología, que se realizaban los días sábados a la mañana por que durante la semana "había mucho que hacer", tenía un espíritu crítico, analítico, una capacidad de observación sagaz y juicio sereno, realmente nos hacía pensar. Seguramente muchas de las generaciones de cardiólogos que pasaron por su servicio conocieron un hombre de bien y recibieron una enseñanza no solo de la cardiología si no de humanismo y de vida; de ahí la admiración y el respeto que sienten los que fueron sus discípulos cardiólogos. Fue hombre con una sólida educación, amplias bases morales y excelentes valores humanísticos. Supo desarrollar con gran vocación de servicio y generosidad sus amplias cualidades y capacidades, y de esa manera, apoyándose en su espíritu organizativo y emprendedor, logró culminar exitosamente las acciones que emprendió en su vida.

Revista Methodo: Investigación Aplicada a las Ciencias Biológicas. Universidad Católica de Córdoba. Jacinto Ríos 571 Bo Gral. Paz. X5004FXS. Córdoba. Argentina. Tel.: (54) 351 4517299 / Correo: methodo@ucc.edu.ar / Web: methodo.ucc.edu.ar | SEMBLANZA Rev. Methodo 2021;6(3):145-146. 
También trabajó, casi desde su fundación en el Hospital Aeronáutico Córdoba. Allí fue jefe del Servicio de Clínica Médica dónde nuevamente su incansable personalidad lo llevó a crear una de las primeras Residencias de Clínica Médica en Córdoba.

En el ámbito universitario fue profesor de Semiología y de Patología Médica en la Facultad de Medicina, actualmente Facultad de Ciencias de la Salud, de la Universidad Católica de Córdoba. También se desempeñó en ese ámbito como Vicedecano durante los años 1969 a 1973. La docencia fue tal vez la pasión en su vida, noches sin dormir preparando conferencias o estudiando por alguna enfermedad de sus pacientes, a veces relegando sus horas de descanso, esparcimiento y pocas veces hasta la familia.

Durante los años que impartió clases frente a grupos de pre y postgrado fue maestro generoso, inspirador y guía para muchos que encontraron en él un amigo y consejero.

Promovió infatigablemente eventos científicos/ académicos de medicina, cursos y congresos.
Participo en muchos de ellos como presidente o coordinador y presento numerosos trabajos de investigación, uno de los cuales le valió el premio "Mariano Castex" otorgado por la Academia Nacional de Medicina de Buenos Aires al mejor trabajo de investigación en el año 1966.

Trabajó hasta pocas semanas antes de su fallecimiento, luego de una larga dolencia, en el mes de octubre de 1989.

Queda en el espíritu de los que fuimos sus alumnos, en cualquier de las instancias educativas, su gran capacidad de observar, analizar y de emitir el juicio clínico con la palabra pensada y justa.

Prof. Dr. Marcelo Miguel Rusculleda

(Universidad Católica de Córdoba, Facultad de Ciencias de la Salud).

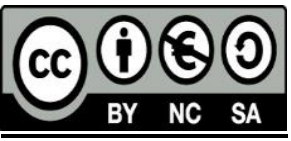

